\title{
Synthesis, Characterization and Single Crystal Studies of 3-cyclopropyl-3, 4-dihydroquinazolin-2(1H)-one
}

\author{
NITINKUMAR S. SHETTY1', NADAF Y. $F^{2}$, \\ DINESH BILEHAL ${ }^{3}$, V SHYAMKUMAR ${ }^{4}$ and SANTOSH L. GAONKAR ${ }^{1 *}$
'Department of Chemistry, Manipal Institute of Technology, Manipal University,Manipal-576104, India.
${ }^{2}$ Department of Physics and Research Center,
Maharani Science College for Womens, Bangalore - 560 001. India.
${ }^{3}$ Department of Chemistry, Reva University, Bangalore-560064, India.
${ }^{4}$ Department of Biotechnology, Karnataka University, Dharwad-580003, India.
${ }^{*}$ Corresponding author E-mail: gaonkarslg@ rediffmail.com

http://dx.doi.org/10.13005/ojc/320544

(Received: August 05, 2016; Accepted: September 10, 2016)

\begin{abstract}
The paper describes industrially scalable synthesis and single crystal studies of 3-cyclopropyl3,4-dihydroquinazolin-2(1H)-one 4, a versatile intermediate in the synthesis of number of biologically active compounds. The target compound has been characterized by LC-MS, ${ }^{1} \mathrm{H}$ NMR and IR. The crystal structure analysis shows that the title compound crystallizes in monoclinic class under the space group P $121 / \mathrm{n} 1$ with cell parameters, $a=10.273(2) \AA$, $b=8.3227(19) \AA, c=11.623(3) \AA$, $\beta=104.980(3)^{\circ}, V=960.0(4) \AA^{3}$ and $Z=4$.
\end{abstract}

Keywords: N, N'-carbonyldiimidazole; 3-cyclopropyl-3, 4-dihydroquinazolin-2(1H)-one .

\section{INTRODUCTION}

Quinazoline derivatives are known for their anticonvulsant ${ }^{1}$, antiinflammatory ${ }^{2}$, and insecticidal ${ }^{3}$ activities. There are many marketed drugs like Balaglitazone, Nolatrexed, and Verubulin containing quinazoline moiety in them ${ }^{4,5}$. Many more are under clinical trial ${ }^{6}$. Similarly, several patents revealing applications of cyclopropylamine derivatives have whipped a curiosity among researchers. Combination of quinazolone and cyclopropane can form an interesting moiety. N,N'-carbonyldiimidazole (CDI) is observed to work in stereoselective acylation and also as a coupling agent ${ }^{7}$. The reagent is easily handled and the imidazole byproduct formed is harmless. This imidazole is easily removed due to its solubility in a number of solvents including water, alcohol, chloroform and ether. In the case of CDI, no oxidation is detected and no decomposition of THF occurs. Quinazolin-2(1H)-one is prepared by the cyclization of an aniline derivative carrying cyclopropane moiety. CDI not just acts as a cyclizing 
agent but also inserts acyl group into the structure. In continuation to our work on the development of new reagents and bioactive molecules ${ }^{8-13}$, we report herein the synthesis and crystal structure of the fused heterocycle 3-cyclopropyl-3, 4-dihydroquinazolin$2(1 H)$-one.

\section{MATERIALS AND METHODS}

\section{Chemistry}

The melting points are determined on Thomas Hoover apparatus and are uncorrected.
IR $(\mathrm{KBr})$ spectra are recorded on Shimadzu 8300 Fourier transform infrared spectrometer. ${ }^{1} \mathrm{H}$ NMR spectra are recorded on Bruker AM $400 \mathrm{MHz}$ spectrometer using $\mathrm{CDCl}_{3}$ as solvent and TMS as an internal standard (Chemical shift in ppm). Mass spectral (MS) analysis is carried out on Agilent 6520 ESIQTOFMS with ionization source ESIQTOF and acetonitrile as solvent (110 volts). Elemental analyses are obtained on a Vario-EL instrument. Thin layer chromatography (TLC) is conducted on 0.25 $\mathrm{mm}$ silica gel plates $\left(60 \mathrm{~F}_{254}\right.$, Merck). Visualization is made with ultraviolet light.

Table 1: Experimental X-ray crystallography data collection and structure refinement of 4

\begin{tabular}{|c|c|c|}
\hline Chemical formula & $\mathrm{C}_{11} \mathrm{H}_{12} \mathrm{~N}_{2} \mathrm{O}$ & \\
\hline Formula weight & 188.23 & \\
\hline Temperature & $296(2) \mathrm{K}$ & \\
\hline Wavelength & $0.71073 \AA$ & \\
\hline Crystal system & monoclinic & \\
\hline Space group & P $121 /$ n 1 & \\
\hline \multirow[t]{3}{*}{ Unit cell dimensions } & $a=10.273(2) \AA$ & $\alpha=90^{\circ}$ \\
\hline & $\mathrm{b}=8.3227(19) \AA$ & $\beta=104.980(3)^{\circ}$ \\
\hline & $c=11.623(3) \AA$ & $\gamma=90^{\circ}$ \\
\hline Volume & $960.0(4) \AA ̊ 3$ & \\
\hline Z & 4 & \\
\hline Density (calculated) & $1.288 \mathrm{Mg} / \mathrm{cm} 3$ & \\
\hline Absorption coefficient & $0.085 \mathrm{~mm}-1$ & \\
\hline$F(000)$ & 392 & \\
\hline Theta range for data collection & 2.36 to $25.17^{\circ}$ & \\
\hline Index ranges & $-12<=\mathrm{h}<=12,-9<=\mathrm{k}<=9,-11<=\mathrm{k}<=13$ & \\
\hline Reflections collected & 6541 & \\
\hline Coverage of independent reflections & $99.80 \%$ & \\
\hline Absorption correction & multi-scan & \\
\hline Structure solution technique & direct methods & \\
\hline Structure solution program & SHELXS-97 (Sheldrick, 2008) & \\
\hline Refinement method & Full-matrix least-squares on $\mathrm{F}^{2}$ & \\
\hline Refinement program & SHELXL-97 (Sheldrick, 2008) & \\
\hline Function minimized & $\Sigma w\left(F_{0}^{2}-F_{c}^{2}\right)^{2}$ & \\
\hline Data / restraints / parameters & $1715 / 0 / 127$ & \\
\hline Goodness-of-fit on $F^{2}$ & 1.486 & \\
\hline$\Delta / \sigma_{\max }$ & 0.081 & \\
\hline \multirow[t]{2}{*}{ Final $R$ indices } & 1359 data; $\mid>2 \sigma(I)$ & $\mathrm{R} 1=0.0650, \mathrm{wR} 2=0.1920$ \\
\hline & all data & $\mathrm{R} 1=0.0639, w R 2=0.1328$ \\
\hline Weighting scheme & $\begin{array}{l}\mathrm{W}=1 /\left[\sigma^{2}\left(\mathrm{~F}_{\circ}^{2}\right)+(0.0835 \mathrm{P})^{2}+0.2218 \mathrm{P}\right. \\
\text { where } \mathrm{P}=\left(\mathrm{F}_{0}^{2}+2 \mathrm{~F}^{2}\right) / 3\end{array}$ & \\
\hline Largest diff. peak and hole & 0.557 and -0.493 eÅ-3 & \\
\hline R.M.S. deviation from mean & 0.078 eÅ-3 & \\
\hline
\end{tabular}

This structure is deposited with the Cambridge Structural Data Base having CCDC NO. 1417597. 
1 - cyclopropyl-N-(2-nitrobenzyl) methanamine (2): A solution of 2-nitrobenzylbromide $1(5 \mathrm{~g}, 0.023 \mathrm{~mol})$ in toluene $(15 \mathrm{~mL})$ is added dropwise to a solution of cyclopropylamine (13.21 $\mathrm{mL}, 0.23 \mathrm{~mol})$ in toluene $(30 \mathrm{~mL})$ at $25-30^{\circ} \mathrm{C}$ for 60 minutes. The reaction mass is stirred at room temperature for 45 minutes. Completion of reaction is marked by TLC analysis with hexane: ethyl acetate $=(1: 1)$ as mobile phase. $10 \%$ aqueous sodium bicarbonate solution is added $(15 \mathrm{~mL})$, stirred and the two layers are separated. The organic layer is washed with water $(10 \mathrm{~mL})$, followed by brine solution $(10 \mathrm{~mL})$. The toluene layer containing 1-cyclopropyl$\mathrm{N}$-(2-nitrobenzyl)methanamine $\mathbf{2}$ is directly taken to the next step. 2-\{[(cyclopropylmethyl)amino]methyl $\}$ aniline (3): The toluene extract with 1-cyclopropyl$\mathrm{N}$-(2-nitrobenzyl)methanamine 2 is reduced in the presence of $10 \% \mathrm{Pd} / \mathrm{C}$ (50\% wet) catalyst in IPA. After $3 \mathrm{~h}$ stirring at room temperature, the catalyst is filtered off and solvent is removed under vacuum to provide 2-\{[(cyclopropylmethyl)amino]methyl $\}$ aniline 3 (3.2 g, $0.018 \mathrm{~mol})$ with m.p. $102-104^{\circ} \mathrm{C}$. IR (KBr): $v_{\max } 3145,2951,1674,1412 ;{ }^{1} \mathrm{H}$ NMR $\left(\mathrm{CDCl}_{3}, 400 \mathrm{MHz},\right): \delta=0.18-0.29(\mathrm{~m}, 2 \mathrm{H}), 0.49-0.53$ $(\mathrm{m}, 2 \mathrm{H}), 0.91-1.06(\mathrm{~m}, 1 \mathrm{H}), 2.71(\mathrm{~s}, 2 \mathrm{H}), 3.53(\mathrm{~s}, 2 \mathrm{H})$, $4.21(\mathrm{~s}, 1 \mathrm{H}), 7.69-8.76(\mathrm{~m}, 4 \mathrm{H})$. El-MS (110 V) $\mathrm{m} / \mathrm{z}$ (\%):163.24 (M+, 100). Anal. Calcd. for $\mathrm{C}_{10} \mathrm{H}_{14} \mathrm{~N}_{2}: \mathrm{C}$, 74.03; H, 8.70; N, 17.27. Found: C, 74.06; H, 8.77; $\mathrm{N}, 17.22$.<smiles>Nc1ccccc1CNC1CC1Cc1cccc(CNC2CC2)c1CNC1CC1</smiles>

Table 2: Atomic coordinates and equivalent isotropic atomic displacement parameters (Å2) of 4 .

\begin{tabular}{ccccc}
\hline & $\mathbf{x} / \mathbf{a}$ & $\mathbf{y} / \mathbf{b}$ & $\mathbf{z} / \mathbf{c}$ & $\mathbf{U}(\mathbf{e q})$ \\
\hline O1 & $0.82588(18)$ & $0.9804(2)$ & $0.92008(15)$ & $0.0479(6)$ \\
N1 & $0.78064(19)$ & $0.0632(3)$ & $0.72761(17)$ & $0.0387(6)$ \\
N2 & $0.9978(2)$ & $0.0651(3)$ & $0.84833(18)$ & $0.0448(6)$ \\
C1 & $0.2253(3)$ & $0.2784(4)$ & $0.7057(3)$ & $0.0526(8)$ \\
C2 & $0.1449(3)$ & $0.2932(4)$ & $0.5908(3)$ & $0.0566(8)$ \\
C3 & $0.0165(3)$ & $0.2300(4)$ & $0.5631(2)$ & $0.0517(8)$ \\
C4 & $0.9672(2)$ & $0.1536(3)$ & $0.6482(2)$ & $0.0392(6)$ \\
C5 & $0.8295(2)$ & $0.0809(4)$ & $0.6211(2)$ & $0.0458(7)$ \\
C6 & $0.6434(2)$ & $0.0108(3)$ & $0.7094(2)$ & $0.0432(7)$ \\
C7 & $0.5339(3)$ & $0.1122(4)$ & $0.6355(2)$ & $0.0521(8)$ \\
C8 & $0.5537(3)$ & $0.1041(4)$ & $0.7666(3)$ & $0.0567(8)$ \\
C9 & $0.1774(3)$ & $0.2023(3)$ & $0.7910(2)$ & $0.0461(7)$ \\
C10 & $0.0481(2)$ & $0.1407(3)$ & $0.7624(2)$ & $0.0372(6)$ \\
C11 & $0.8654(2)$ & $0.0325(3)$ & $0.8358(2)$ & $0.0370(6)$ \\
\hline
\end{tabular}

$\mathrm{U}(\mathrm{eq})$ is defined as one third of the trace of the orthogonalized $\mathrm{Uij}_{\mathrm{ij}}$ tensor 
3-cyclopropyl-3,4-dihydroquinazolin-2(1H)one (4) : N,N'-carbonyldiimidazole (2.4 g, $0.01 \mathrm{~mol})$ is added to $2-\{[$ (cyclopropylmethyl)amino $]$ methyl $\}$ aniline $(5.3 \mathrm{~g}, 0.03 \mathrm{~mol})$ in THF $(30 \mathrm{~mL})$ at $50^{\circ} \mathrm{C}$. Stirred for $4 \mathrm{~h}$ and cooled. Two layers are separated and organic layer is given a water wash. Solvent is removed and the mass is stirred with IPA at $40^{\circ} \mathrm{C}$ and then cooled to $5^{\circ} \mathrm{C}$. White crystalline solid formed

Table 3: Bond lengths $(\AA)$ of 4

\begin{tabular}{lccc}
\hline $\mathrm{O} 1-\mathrm{C} 11$ & $1.232(3)$ & $\mathrm{N} 1-\mathrm{C} 11$ & $1.356(3)$ \\
$\mathrm{N} 1-\mathrm{C} 6$ & $1.439(3)$ & $\mathrm{N} 1-\mathrm{C} 5$ & $1.459(3)$ \\
$\mathrm{N} 2-\mathrm{C} 11$ & $1.357(3)$ & $\mathrm{N} 2-\mathrm{C} 10$ & $1.389(3)$ \\
$\mathrm{N} 2-\mathrm{H} 2$ & 0.86 & $\mathrm{C} 1-\mathrm{C} 9$ & $1.370(4)$ \\
$\mathrm{C} 1-\mathrm{C} 2$ & $1.382(4)$ & $\mathrm{C} 1-\mathrm{H} 1$ & 0.93 \\
$\mathrm{C} 2-\mathrm{C} 3$ & $1.379(4)$ & $\mathrm{C} 2-\mathrm{H} 2 \mathrm{~A}$ & 0.93 \\
$\mathrm{C} 3-\mathrm{C} 4$ & $1.377(3)$ & $\mathrm{C} 3-\mathrm{H} 3$ & 0.93 \\
$\mathrm{C} 4-\mathrm{C} 10$ & $1.376(3)$ & $\mathrm{C} 4-\mathrm{C} 5$ & $1.496(3)$ \\
$\mathrm{C} 5-\mathrm{H} 5 \mathrm{~A}$ & 0.97 & $\mathrm{C} 5-\mathrm{H} 5 \mathrm{~B}$ & 0.97 \\
$\mathrm{C} 6-\mathrm{C} 8$ & $1.487(4)$ & $\mathrm{C} 6-\mathrm{C} 7$ & $1.489(4)$ \\
$\mathrm{C} 6-\mathrm{H} 6$ & 0.98 & $\mathrm{C} 7-\mathrm{C} 8$ & $1.486(4)$ \\
$\mathrm{C} 7-\mathrm{H} 7$ & 0.93 & $\mathrm{C} 8-\mathrm{H} 8$ & 0.93 \\
$\mathrm{C} 9-\mathrm{C} 10$ & $1.382(4)$ & $\mathrm{C} 9-\mathrm{H} 9$ & 0.93 \\
\hline
\end{tabular}

is 3-cyclopropyl-3, 4-dihydroquinazolin-2(1H)-one 4 (3.2 g, $0.01 \mathrm{~mol}$ ) with m.p. $146-148^{\circ} \mathrm{C}$. IR (KBr): $v_{\max } 3109,2926,1712,1665,1408 ;{ }^{1} \mathrm{H} \mathrm{NMR}\left(\mathrm{CDCl}_{3}\right.$, $400 \mathrm{MHz},): \delta=0.15-0.22(\mathrm{~m}, 2 \mathrm{H}), 0.34-0.41(\mathrm{~m}, 2 \mathrm{H})$,

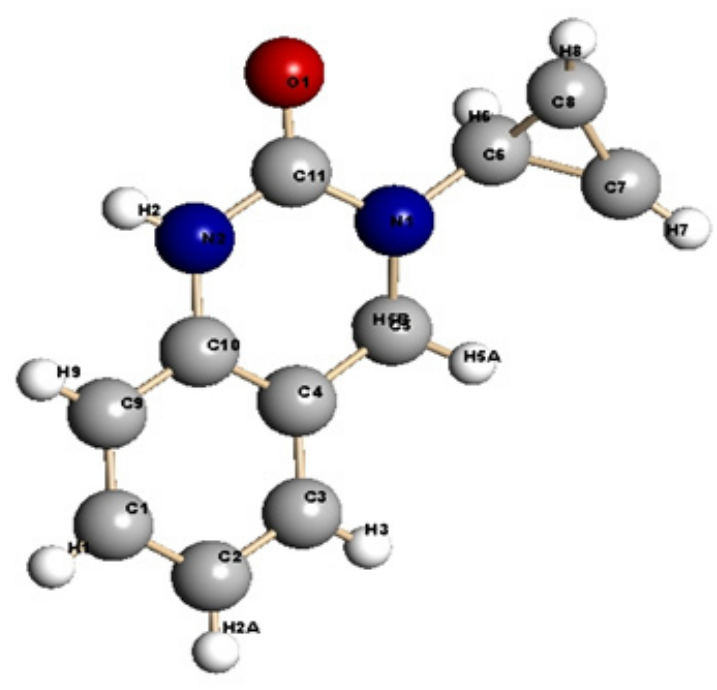

Fig. 1: ORTEP diagram of the compound 4 at $50 \%$ probability with atom numbering

Table 4: Bond angles $\left({ }^{\circ}\right)$ of compound 4

\begin{tabular}{lccc}
\hline C11-N1-C6 & $116.7(2)$ & C11-N1-C5 & $121.8(2)$ \\
C6-N1-C5 & $116.4(2)$ & C11-N2-C10 & $124.2(2)$ \\
C11-N2-H2 & 117.9 & C10-N2-H2 & 117.9 \\
C9-C1-C2 & $120.2(3)$ & C9-C1-H1 & 119.9 \\
C2-C1-H1 & 119.9 & C3-C2-C1 & $119.2(3)$ \\
C3-C2-H2A & 120.4 & C1-C2-H2A & 120.4 \\
C4-C3-C2 & $121.0(3)$ & C4-C3-H3 & 119.5 \\
C2-C3-H3 & 119.5 & C3-C4-C10 & $119.1(2)$ \\
C3-C4-C5 & $122.6(2)$ & C10-C4-C5 & $118.3(2)$ \\
N1-C5-C4 & $112.1(2)$ & N1-C5-H5A & 109.2 \\
C4-C5-H5A & 109.2 & N1-C5-H5B & 109.2 \\
C4-C5-H5B & 109.2 & H5A-C5-H5B & 107.9 \\
N1-C6-C8 & $118.2(2)$ & N1-C6-C7 & $118.6(2)$ \\
C8-C6-C7 & $59.93(19)$ & N1-C6-H6 & 116.1 \\
C8-C6-H6 & 116.1 & C7-C6-H6 & 116.1 \\
C8-C7-C6 & $59.98(18)$ & C8-C7-H7 & 150.0 \\
C6-C7-H7 & 150.0 & C7-C8-C6 & $60.10(18)$ \\
C7-C8-H8 & 150.0 & C6-C8-H8 & 150.0 \\
C1-C9-C10 & $120.0(3)$ & C1-C9-H9 & 120.0 \\
C10-C9-H9 & 120.0 & C9-C10-C4 & $120.4(2)$ \\
C9-C10-N2 & $120.6(2)$ & C4-C10-N2 & $119.0(2)$ \\
O1-C11-N1 & $122.6(2)$ & O1-C11-N2 & $120.8(2)$ \\
N1-C11-N2 & $116.6(2)$ & & \\
\hline
\end{tabular}


0.85- $0.97(\mathrm{~m}, 1 \mathrm{H}), 2.54(\mathrm{~s}, 2 \mathrm{H}), 7.42-8.3(\mathrm{~m}, 4 \mathrm{H})$, 10.23 (s, 1H). El-MS (110 V) m/z (\%): $189.21(\mathrm{M}+$, 100). Anal. Calcd. for C11H12N2O: C, 70.19; H, 6.43; N, 8.50. Found: C, 70.12; H, 6.40; N, 8.55.

\section{X-Ray Data Collection}

A specimen of title compound with molecular formula $\mathrm{C}_{11} \mathrm{H}_{12} \mathrm{~N}_{2} \mathrm{O}$ was used for the $\mathrm{X}$-ray crystallographic analysis. The $\mathrm{X}$-ray intensity data were measured. A total of 1261 frames were collected. The total exposure time was 3.50 hours.
The frames were integrated with the Bruker SAINT Software package using a narrow-frame algorithm. Data were corrected for absorption effects using the multi-scan method (SADABS). The ratio of minimum to maximum apparent transmission was 0.906 . The structure was solved and refined using the Bruker SHELXTL Software Package, using the space group $P 121 / n 1$, with $Z=4$ for the formula unit, $\mathrm{C}_{11} \mathrm{H}_{12} \mathrm{~N}_{2} \mathrm{O}$. Crystal data and structure refinement details are tabulated in Table 1. The final positional coordinates of all the atoms, bond distances

Table 5: Anisotropic atomic displacement parameters (Å2) of compound 4

\begin{tabular}{ccccccc}
\hline & U11 & U22 & U33 & U23 & U13 & U12 \\
\hline O1 & $0.0450(11)$ & $0.0623(13)$ & $0.0379(10)$ & $0.0132(9)$ & $0.0133(8)$ & $0.0002(9)$ \\
N1 & $0.0328(11)$ & $0.0488(14)$ & $0.0344(11)$ & $0.0031(9)$ & $0.0083(8)$ & $-0.0022(9)$ \\
N2 & $0.0343(11)$ & $0.0633(16)$ & $0.0341(11)$ & $0.0110(10)$ & $0.0040(9)$ & $-0.0008(10)$ \\
C1 & $0.0376(14)$ & $0.0585(19)$ & $0.0642(19)$ & $0.0047(14)$ & $0.0175(13)$ & $-0.0032(12)$ \\
C2 & $0.0517(17)$ & $0.070(2)$ & $0.0550(18)$ & $0.0089(15)$ & $0.0267(14)$ & $-0.0016(15)$ \\
C3 & $0.0438(15)$ & $0.074(2)$ & $0.0397(15)$ & $0.0079(14)$ & $0.0158(12)$ & $0.0018(14)$ \\
C4 & $0.0378(13)$ & $0.0442(15)$ & $0.0371(14)$ & $0.0005(11)$ & $0.0126(10)$ & $0.0040(11)$ \\
C5 & $0.0393(14)$ & $0.0661(19)$ & $0.0319(13)$ & $0.0011(12)$ & $0.0090(10)$ & $-0.0053(12)$ \\
C6 & $0.0362(13)$ & $0.0409(15)$ & $0.0527(16)$ & $0.0015(12)$ & $0.0120(11)$ & $-0.0056(11)$ \\
C7 & $0.0382(14)$ & $0.073(2)$ & $0.0408(15)$ & $0.0027(14)$ & $0.0021(11)$ & $0.0051(13)$ \\
C8 & $0.0427(15)$ & $0.085(2)$ & $0.0456(16)$ & $-0.0006(15)$ & $0.0172(12)$ & $0.0072(14)$ \\
C9 & $0.0351(13)$ & $0.0536(18)$ & $0.0472(15)$ & $0.0013(12)$ & $0.0064(11)$ & $0.0002(12)$ \\
C10 & $0.0361(12)$ & $0.0384(14)$ & $0.0383(14)$ & $0.0033(11)$ & $0.0115(10)$ & $0.0043(10)$ \\
C11 & $0.0380(13)$ & $0.0386(15)$ & $0.0350(13)$ & $0.0033(10)$ & $0.0104(10)$ & $0.0037(10)$
\end{tabular}

The anisotropic atomic displacement factor exponent takes the form:-2 $\pi^{2}\left[h^{2} a^{* 2} U_{11}+\ldots+2 h k a^{*} b^{*} U_{12}\right]$

Table 6: Hydrogen atomic coordinates and isotropic atomic displacement parameters (Å2) of compound 4

\begin{tabular}{lcccc}
\hline & $\mathbf{x} / \mathbf{a}$ & $\mathbf{y} / \mathbf{b}$ & $\mathbf{z} / \mathbf{c}$ & $\mathbf{U}(\mathbf{e q})$ \\
\hline H2 & 1.0541 & 0.0371 & 0.9137 & 0.054 \\
H1 & 1.3122 & 0.3202 & 0.7252 & 0.063 \\
H2A & 1.1771 & 0.3453 & 0.5329 & 0.068 \\
H3 & 0.9623 & 0.2390 & 0.4857 & 0.062 \\
H5A & 0.7675 & 0.1484 & 0.5641 & 0.055 \\
H5B & 0.8315 & -0.0237 & 0.5848 & 0.055 \\
H6 & 0.6284 & -0.1056 & 0.7040 & 0.052 \\
H7 & 0.4873 & 0.1517 & 0.5615 & 0.063 \\
H8 & 0.5284 & 0.1349 & 0.8347 & 0.068 \\
H9 & 1.2319 & 0.1922 & 0.8681 & 0.055 \\
\hline
\end{tabular}

and bond angles are accounted in Tables 2-4 respectively. Anisotropic atomic displacement and Hydrogen atomic coordinates along with isotropic atomic displacement parameters are depicted in Tables 5 and 6 respectively.

\section{RESULTS AND DISCUSSION}

The title compound is synthesized as per scheme 1.2-nitrobenzylbromide 1 and cyclopropylamine are reacted to afford 1-cyclopropyl$\mathrm{N}$-(2-nitrobenzyl)methanamine 2, which is reduced to $2-\{[$ (cyclopropylmethyl)amino]methyl\}aniline 3 . This reduced product is then cyclized to the desired 3-cyclopropyl-3, 4-dihydroquinazolin-2(1H)-one 4 by CDI without getting any undesired side products. 
Structures of the synthesized compounds are characterized by spectral and elemental analyses. The IR spectrum of 3-cyclopropyl-3, 4-dihydroquinazolin-2(1H)-one 4 shows the characteristic peaks at 3109 for $\mathrm{NH}$ stretching and 1712 for $\mathrm{C}=\mathrm{O}$ stretching. ${ }^{1} \mathrm{H}$ NMR spectrum shows the characteristic signal at $\delta 10.23$ for the $\mathrm{NH}$ of quinazolone. LC-MS analysis confirms that the value of the molecular ion peak is in agreement with the calculated formula weight of the title compound.

Figure 1 stands for the ORTEP diagram of the compound 4 at $50 \%$ probability with atom numbering. The integration of the data using a monoclinic unit cell yielded a total of 6541 reflections to a maximum $\theta$ angle of $25.17^{\circ}$ (0.84 Å resolution), of which 1715 were independent (average redundancy 3.814 , completeness $\left.=99.8 \%, R_{\text {sig }}=3.02 \%\right)$ and $1359(79.24 \%)$ were greater than $2 \sigma\left(\mathrm{F}^{2}\right)$. The final cell constants of $\underline{a}=10.273(2) \AA ⿻ 上 丨=8.3227(19)$ $\AA, \underline{c}=11.623(3) \AA, \beta=104.980(3)^{\circ}$, volume $=$ $960.0(4) \AA^{3}$, are based upon the refinement of the $\mathrm{XYZ}$-centroids of 2105 reflections above $20 \sigma(\mathrm{I})$ with $4.723^{\circ}<2 \theta<49.16^{\circ}$. The final anisotropic full-matrix least-squares refinement on $\mathrm{F}^{2}$ with 127 variables converged at $\mathrm{R} 1=6.50 \%$, for the observed data and $w R 2=20.36 \%$ for all data. The goodness-of-fit was 1.486. The largest peak in the final difference electron density synthesis was $0.557 \mathrm{e}^{-/} \AA^{3}$ and the largest hole was -0.493 e/ $/ \AA^{3}$ with an RMS deviation of $0.078 \mathrm{e}^{-} / \AA^{3}$. On the basis of the final model, the calculated density was $1.288 \mathrm{~g} / \mathrm{cm}^{3}$ and $F(000)$, $392 \mathrm{e}^{-}$.

\section{CONCLUSION}

In conclusion, we report the synthesis of 3-cyclopropyl-3, 4-dihydroquinazolin-2(1H)-one 4. CDI is used as efficient reagent for cyclization of amines to quinazolin-2(1H)-one. Work up procedure is easily accessible for lab conditions to get good yield and purity. Modern analytical techniques have characterized the structure of the title compound and single crystal X-ray of the compound is presented.

\section{ACKNOWLEDGMENTS}

The authors are thankful to Manipal Institute of Technology, Manipal for laboratory facilities and Karnatak University, Dharwad for the XRD.

\section{REFERENCES}

1. Ugale, V. G.; Bari, S. B. Eur. J. Med. Chem. 2014, 80, 447-501.

2. Rekha, S. H.; Basavaraj, R. P.; Dayananda, S. B.; Ramesh, S.V.; Kalagouda, B. G.; Prasad, R. D.; Mahesh, M. G.; Subhash, B. P.; Munirathinam, N. Eur. J. Med. Chem. 2010, 45, 2277-2282.

3. Yunyun, Z.; Qi, F.; Fegjuan, D.; Qiaoxiao, L.; Duoyi, W.; Youwei, C.; Lixia, X.; Haibin, S.; Yuxin, L.; Zhengming, L. Bioorg. Med. Chem. 2013, 21, 4968-4975.

4. Theivendren, P. S.; Palanirajan, V. K. Res. In. Pharm. 2011, 1, 1-21.

5. Vijayakumar, B.; Prasanthi, P.; Muni, K. T.; Makesh, K. K.R.: Nishanthi, P.; Nagendramma, M.; Nishanthi, M. Int. J. Med. Chem. Anal. 2013. 3, 10-21.

6. Abida, P. N.; Rana, A.; Imran, M. Int. J. Pharma. Bio. Arc. 2011, 2, 1651-1657.
7. Wang, H.; Ma, J. Y. J. Chem. Pharma. Res. 2012, 4, 580-582.

8. Gaonkar, S. L.; Rai, K. M. L. Tet. Lett, 2005, 6, 5969-5970.

9. Priya, B. S.; Nanjundaswamy, S.; Tejesvi, M. V.; Sarala, G.; Gaonkar, S. L.; Naveen, S.; Shashidhara, P. J.; Rangappa, K. S. Eur. J. Med. Chem, 2006, 41, 1262-1270.

10. Gaonkar, S. L.; Rai, K. M. L.; Prabhuswamy, B. Eur. J. Med. Chem. 2006, 4, 841-846.

11. Gaonkar, S. L.; Shimizu, H. Tetrahedron, 2010, 66, 3314-3317.

12. Mahadevaprasad, T. N,; Gaonkar, S. L; Kamini, K.; Vivek, G. K.; Rajnikant; Shimizu, H.; Sridhar, M. A.; Shashidhara, P. J. Anal. Chem. X-ray Analys. Online, 2012, 28, 2526.

13. Namratha, B.; Gaonkar, S. L. Int. Scholarly Res. Notices, 2014, 2014, 1-7. 